\title{
A Arte Moderna no Brasil e o seu processo de institucionalização
}

\section{Ana Maria Pimenta Hoffmann}

- Universidade Federal, de São Paulo (Unifesp)

\section{Modern Art in Brazil and its process \\ of institutionalization}

\section{Resumo}

Este texto faz uma análise panorâmica do processo de institucionalização da arte moderna no Brasil, acompanhando as principais publicações sobre a arte moderna brasileira nas décadas de 1920 a 1950. Temos com o objetivo fazer uma investigação sobre o uso dos termos 'arte moderna' e 'modernismo' em um conjunto de publicações que abarcam o período de 1922 às primeiras Bienais. Tentarei desta forma, traçar um roteiro de estudo e uma listagem das principais referências bibliográficas da época, fornecendo assim subsídios para pesquisa da história da crítica de arte e da historiografia do modernismo brasileiro a partir de fontes primárias. Buscarei fundamentalmente acompanhar, nesta série de publicações, o processo de institucionalização da arte moderna no Brasil, em especial em São Paulo e no Rio de Janeiro, tendo como critério o desenvolvimento da crítica de arte em textos testemunhais, jornalísticos e acadêmicos que foram posteriormente publicados em formato de livro e que ainda serem como referencia para a historiografia atual.

Pallavras-chave: Arte-Brasil; Arte moderna; Crítica de arte, História da arte.

\section{Abstract}

In this paper an overall analyses of the institutionalization process of modern art in Brazil is presented. The main published works on Brazilian modern art from the 1920 s to the 1950 s are reviewed. Our goal is to examine the use of the expressions "modern art" and "modernism" in publications in the period that goes from 1922 (year of the Modern Art Week launched in São Paulo) to the earliest São Paulo Art Biennials. We suggest a navigational route map of sorts and a list of the main bibliographical references of that era and present thus the elements for a debate on the history of art critique in Brazil and on the historiography of Brazilian modernism that should be based on primary sources. Our attempt is, basically, to follow, in those publications, the institutionalization process of modern art in Brazil, in particular in São Paulo and in Rio de Janeiro, taking as guide the development of art critique as it appears in journalistic and academic testimonies published in books in those years and that are still works of reference in our days.

Keywords: Art-Brazil; Modern art; Art critique; Art history. 


\section{n $n \cdot t$
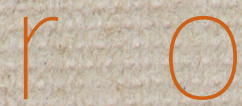 \\ d
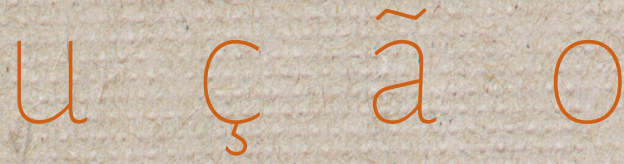

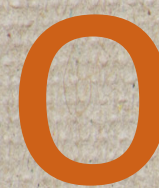

que é a arte moderna brasileira? Como ela se desenvolveuno Brasil? Qual o significado deste termo e dos imensos acervos organizados para explicá-lo? Como podemos entender historicamente esta produção que propôs a ruptura com a tradição artística ocidental e que necessita desta mesma tradição para um entendimento verdadeiro? Como vivenciar esta produção escapando das camadas de equívocos geradas pela imensa divulgação de imagens dos ícones da arte modernista proporcionada pela sociedade do entretenimento e da informação digital? Estas são questões que surgem necessariamente na história
Acredito que um dos

debates mais importantes na historiografia da arte moderna éa discussão em torno do processo de institucionalização desta arte antipassadista: Isto é, como que gradativamente, e muitas vezes de modo. paradoxal, a arte de vanguarda foi buscando éspaço e sen do assimilada pelas instâncias do poder institucionalizado. da arte moderna, e é sobre elas que eu gostaria de me debruçar, tratando particularmente do caso brasileiro.

Acredito que um dos debates mais importantes na historiografia da arte mo- derna é a discussão em torno do processo de institucionalização desta arte antipassadista. Isto é, como que gradativamente, e muitas vezes de modo paradoxal, a arte de vanguarda foi buscando espaço e sendo assimilada pelas instâncias do poder institucionalizado.

Penso neste caso, nas exposições oficiais, os salões organizados pelas escolas de belas artes ou por outras instituições; na apreciação do público especializado, ou seja, a crítica de arte; e na divulgação junto aos meios de comunicação, jornais e publicações em geral. Acompanhar este processo é fundamental para termos uma visão crítica da história da historiografia artística, pois muitas vezes, as narrativas - com sua particular eleição de fatos e personagens -, repete, ou tem como principal fonte, este processo de institucionalização da arte. Sobre os desafios na análise do mo- 
dernismo no Brasil, avalia Anateresa Fabris (2010, p. 9):

Analisar a modernidade hoje em dia é uma tarefa complexa, que pressupõe, de um lado, uma visão crítica capaz de ir além das teorizações que constituem seu autorretrato mítico, e de outro uma atenção redobrada para não cair em muitas simplificações do discurso pós-moderno e de sua vontade de erguer-se como antagonista e superador de uma situação cultural, para a qual são propostas categorias distintivas, não raro permeadas de falsas contraposições. O que fazer para não cair em tais armadilhas e tentar construir uma ideia de modernidade que faça jus a suas conquistas sem se deixar contaminar pela autocelebração ou pela relativização contrastiva? A tarefa que se impõe é ainda mais necessária e difícil no Brasil, pois boa parte do que conhecemos do modernismo foi produzida por seus protagonistas e por uma geração de críticos e historiadores empenhados na defesa da causa da arte moderna que frequentemente esposou as razões da primeira hora sem contestá-las ou questioná-las muito timidamente.

\section{A institucionalização da Arte Moderna no Brasil}

O processo de institucionalização da Arte Moderna no Brasil começou com a Semana de Arte Moderna em 1922 , evento que, nas palavras de Mario de Andrade (1963 [1942], p. 265), "foi planejado para ser histórico"1. Este processo será consolidado nas Bienais dos anos de 1950 , em que os principais nomes do modernismo brasileiro são contemplados com prêmios e são objeto de salas especiais e publicações. O processo de organização de um discurso em torno da arte moder-

na aconteceu concomitantemente em outros países da América Latina e nos Estados Unidos, e muitas vezes foi abrigado nos novíssimos múseus de arte moderna, que tiveram como modelo o Museu de Arte Moderna de Nova York, na gestão do historiador da arte Alfred Barr².

Serão analisados os seguintes textos: A emoção estética n̦a arte, de Graça Aranha, publicado em 1925; os artigos da Klaxon e da Revista Anual do Salão de Maio de 1938; A Pintura Moderna no Brasil, de Luis Martins, publicado em 1937; O movimento modernista, de Mario de Andrade, de 1942; A marginalidade da Pintura Moderna, de Ser-

1 Todos os estudos sobre a Semana de Arte Moderna de 1922 são devedores da dissertação de mestrado da Profa. Aracy Amaral, intitulada Artes plásticas na Semana de 22: subsídios para uma historia da renovação das artes no Brasil, e publicada pela primeira vez em 1970. 2 Cf. Kantor (2002). 
gio Milliet, publicado em Pintura quase sempre, de 1944, e finalmente os livros Retrato da Arte Moderna no Brasil (1948), de Lourival Comes Machado, e Panorama da Arte Moderna (1952), de Mario Pedrosa.

No conjunto destas publicações, temos que separar os textos de ocasião, que objetivavam a divulgação de ideias, como a conferência de Graça Aranha e os textos de Luís Martins; dos que se caracterizam por serem depoimentos, como no caso dos textos de Mario de Andrade e os dos modernistas na revista do Terceiro Salão de Maio; e aqueles com formato acadêmico e didático, como em Sergio Milliet, Lourival Gomes Machado e Mario Pedrosa. Cada um deles foi produzido em contextos bastante distintos, e objetivavam diferentes públicos, mas ficaram para a história na sua função de registro impresso do debate crítico e teórico sobre a arte moderna no Brasil, na forma mais oficial e duradora - o livro -, e modularam as publicações subsequentes. $O$ objetivo da minha análise é promover uma observância das fontes primárias da história da arte moderna no Brasil, no debate da crítica de arte e suas relações com o contexto institucional da arte, com suas instituições - em especial os museus e as Bienais - , e seus protagonistas.

Vale lembrar que a Semana de Arte Moderna de 1922 foi um processo autocelebrativo, cujas publicações que analisaremos reiteram. Neste sentido, existe um esforço de estabelecer uma narrativa em torno da produção modernista e de seu processo de institucionalização, que será capitulado pelas Bienais do Museu de Arte Moderna de São Paulo (1951-1961). Lembro também que é fenômeno relativamente recente na historiografia artística a reavaliação destas fontes testemunhais e bibliográficas, e a ampliação do espeçtro das manifestações relacionadas ao processo de institucionalização da arte moderna ${ }^{3}$.

A Semana de Arte Moderna de 1922 foi um festival de artes planejado para se tornar mito-fundador da modernização das artes no Brasil, principalmen-

3 Cf. Lourenço (1999). 
te em São Paulo. Foram três os "atrativos" do evento: a música, a exposição de artes (pintura, escultura, desenhos e arquitetura - com desenhos e uma maquete), mas principalmente a polêmica na crítica de arte e na crítica literária.

Foi nas cidades de São Paulo e Rio de Janeiro que o modernismo ganhou contornos institucionais mais claros, e mais precocemente, mas não podemos deixar de mencionar que, dentro da historiografia, tem-se afirmado a necessidade de fazer-se uma revisão da história do modernismo no Brasil, em que sejam contempladas as diversas produções e circunstâncias de todo o território nacional, assim como suas conexões com o contexto europeú, norte e latino-americano.

\section{As décadas de 1920 e 1930: a Semana, os Salões de Maio e outras publicações testemunhais}

A primeira publicação que gostaria de analisar é a conferência inaugural da Semána de Arte Moderna, proferida por Graça Aranha em 1922, intitulada A emoção estética na arte, e posteriormente publicada no livro Espírito Moderno, em 1925. Literato e diplomata, o autor de Canãa (1902) foi um dos organizadores da Semana e divulgador do pensamento modernista, tendo traduzido e prefaciado a publicação do Manifesto Futurista de Filippo Marinetti (ARANHA, 1926).

Em Espírito Moderno é publicada outra conferência, proferida na Academia Brasileira de Letras: O Espirito Acadêmico, com respostas ao relator do projeto de dicionário da Academia; ao lado de textos críticos dedicados a clássicos da literatura europeia, como Marcel Proust e Dostoievsky. Vale lembrar que Graça Aranha rompe com a Academia em 1924, atitude decorrente de seu espírito renovador nas letras e na artes no Brasil.

No texto A emoção estética na arte, o autor faz uma espécie de pregação por uma arte nova e antipassadista, muitas vezes com fontes e argumentações contraditórias. Ao definir a arte moderna, o autor escreve que "cada um é livre de criar e manifestar a sua fantasia íntima desencadeada de toda 
a regra, de toda sanção. O canon e a lei são substituídos pela liberdade absoluta - que nos revela, por mil extravagâncias, maravilhas que só a liberdade sabe gerar" e "quando procura emoção estética na Arte moderna, afirmou- se que o supremo movimento artístico daquele instante se caracterizava pelo mais livre e fecundo subjetivismo" (ARANHA, 1925). Assim, podemos afirmar com certa segurança que a fala teve um caráter divulgador do sentimento de renovação do meio artístico e literário vigente entre os organizadores e participantes da Semana, assim como papel importante na divulgação do ideário modernista, apesar de significativas discordâncias com Mario de Andrade 4 .

A segunda metade dos anos 1930 ficou marcada, no ambiente artístico paulista, pela organização e polêmicas que provocou nos Salões de Maio. Inaugurada em 25 de maio de 1937.

4 Na edição do livro "O espírito modernista", de Graça Aranha, presente no Fundo Mario de Andrade, do Instituto de Estudos Brasileiros da Universidade de São Paulo (IEB/ USP), podemos ver as anotaç̃oes a lápis de Mario de Andrade: "quando C. A. isso afirmou eu dei um 'não-apoiado' do meu canto. C. A. até se voltou sorrindo" ou "foi aqui que eu não me contive mais e gritei: não apoiado!". E no final do capítulo anota: "Esta conferência é fragilíssima. Umas ideias vagas, muito gerais a que toda gente que pensar um pouco mais ou menos sabe. Não possui mesmo em igual intensidade aquele esplendor de dicção que é peculiar ao C. A.". no Esplanada Hotel, esta mostra, de vida curta, com somente três edições, teve como grande mérito trazer para a conjuntura de mostras em artes plásticas no Brasil a discussão estética em torno da arte moderna, da figuração e do abstracionismo, além da maciça participação de artistas estrangeiros. Idealizada pelo pintor, professor e crítico acadêmico Quirino da Silva, a mostra trouxe para o contexto brasileiro uma diversidade de tendências e cumpriu a tarefa de colocar os críticos de arte e o público em contato com uma produção artística atual.

O último Salão de Maio, de 1939, após discordâncias entre os organizadores, foi dominado por Flávio de Carvalho, e funcionou como uma revisão dos princípios modernistas e introdução da arte abstrata, discussão que se fazia premente naqueles tempos. Nesta versão foi instituída uma comissão de seleção das obras participantes, de orientação claramente modernista, opondo-se à perspectiva de Quirino da Silva, com quem Flavio de Carvalho havia rompido. Dentro das inúmeras atividades da mostra, foi incluída a publicação da Revista Anual do Salão de Maio, a RASM, de design inovador, com 
uma (desajeitada) capa de alumínio, com extensa documentação fotográfica e artigos de Flávio de Carvalho, Lasar Segall, Anita Malfatti, Guilherme de Almeida, Tarsila do Amaral, Oswald de Andrade Filho, Luis Martins, Rino Levi, e Paulo Mendes de Almeida, entre outros ${ }^{5}$. A dissonância com o formato acadêmico de organização de mostras, essencialmente seletivo, explicita-se no acolhimento amplo das produções modernistas: " $\mathrm{O}$ Salão de Maio apoia e aceita todas as manifestações pertencentes à revolução estética - expressionismo, cubismo, fauvismo, etc - porque, assim fazendo, ele protege a estrutura sobre a qual se assenta o que há de vital na arte de hoje" (RASM, 1938, p. 13).

5 Compuseram a publicação os seguintes textos: Um plano de seis anos, por Flavio de Carvalho; Manifesto do III Salão de Maio 1912, por Lasar Segall); 1917, por Anita Malfatti; História da Semana de Arte Moderna, por Carminha de Almeida; Ideias de 1922, por Guilherme de Almeida; Verdamarelismo, por Cassiano Ricardo; Pintura pau brasil e antropofagia, por Tarsila do Amaral; Da doutrina antropofágica - 1928, por Oswald de Andrade; Recordação do Clube dos Artistas Modernos, por Flavio de Carvalho; A epopeia do Teatro da Experiência e - Bailado do Deus Morto, por Flavio de Carvalho; Rápida noticia sobre o Spam, por Paulo Mendes de Almeida; $7^{\circ}$ e $2^{\circ}$ Salão de Maio, por Oswald de Andrade Filho; O que há de errado na nossa literatura moderna, por Luis Martins; O que há na arquitetura, por Rino Levi; Paisagem da musica brasileira, por Ciro Monteiro Brisolla; A literatura na minha geração, por Sangirardi Júnior; Um nome brasileiro na cinematografia mundial; Catálogo das obras expostas no III Salão de Maio; Notas biográficas dos colaboradores do III Salão de Maio (RASM, 1938).
Com tom claramente provocativo, os textos da revista espelham a polêmica que surgiu em torno da organização desta terceira edição, a começar pelos textos Um plano de 6 anos, escrito por Flávio de Carvalho, com um esquema de desenvolvimento possível da arte moderna, e o Manifesto do III Salão de Maio, de caráter propositivo, em que Lasar Segall, em texto não assinado, apresenta resumo das teorias abstracionistas divulgadas pela revista Circle et Carré sobre a predominância do surrealismo e do abstracionismo nas vanguardas europeias.

Curiosa e significativa é a citação inicial do discurso de Franklin Roosevelt por ocasião da inauguração do novo prédio do Museu de Arte Moderna de Nova York, ocorrida naquele mesmo ano de 1939: "unicamente onde os homens são livres pode a arte florescer e a civilização colher seus furtos" - declaração presente em uma notícia publicada pelo Diário de São Paulo em 1.1 de maio, dando conta da inegável filiação com o meio artístico norte-americano.

Mas o que me interessa nesta publicação são os textos dos modernistas 
Lasar Segall, Anita Malfatti, Tarsila do Amaral e Oswald de Andrade, que fazem uma avaliação da trajetória do meio artístico paulista no caminho para a modernização. Neste sentido, a publicação tem clara intenção de oficializar o projeto do movimento modernista, estabelecendo o roteiro desta institucionalização: as exposições de Segall e Malfatti, em 1913 e 1917 respectivamente; a Semana de Arte Moderna de 1922; o Movimento Pau Brasil e o Clube dos Artistas Modernos (CAM), culminando com o próprio Salão de Maio. Este roteiro será repetido em várias das versões posteriores da história da arte moderna no Brasil.

Os depoimentos de Lasar Segall e Anita Malfatti comovem pela franqueza e seguem mais ou menos o mesmo script: descrevem o período de formação de cada artista - concidentemente, ambos em Berlin -, e os seus descaminhos em relação à academia, para depois tematizar as primeiras exposições individuais de cada um no Brasil, em 1913 e 1917, respectivamente. Na sequência, ambos comentam também certo despreparo do meio brasileiro para com as suas produções comprometidas com as linguagens desen- volvidas pelas vanguardas europeias do início do século XX. Por fim, cada artista relata as suas experiências nos, anos de 1930 no Brasil, para finalizar com uma avaliação da importância da abertura proposta pela arte moderna.

Na mesma publicação, na sequência destes dois depoimentos, temos outros textos igualmente importantes, que cito: o de Carminha de Almeida e de Guilherme de Almeida - contando, respectivamente, um breve relato dos bastidores do evento e as notas feitas pelo autor à época sobre o termo futurismo associado ao grupo 6 . Estes testemunhos oculares da Semana, junto com os relatos de Segall e Malfatti, e textos de Oswald de Andrade e Tarsila do Amaral, completam a teogonia da arte moderna no' Brasil, publicada no catálogo do terceiro e derradeiro Salão de Maio.

Outro momento que me parece crucial na crítica de arte dos anos 1930 , é a publicação do livro de Luís Martins (1937), A pintura moderna no Brasil, no qual o autor publica a conferência pronunciada na Associação dos Artistas Brasileiros, em 5 de junho do ano

6 Para o debate sobre o uso do termo, conferir Fabris (1990). 
anterior. O jovem jornalista e crítico de arte faz uma síntese de sua visão sobre o desenvolvimento da pintura moderna no Brasil.

Em certa medida, o texto tem interesse pela sua precocidade na tentativa de fazer um balanço do debate em torno da arte moderna neste final dos anos 1930, destacando as relações "de alguns valores mais representativos da arte brasileira" (MARTINS, 1937, p. 13), como Tarsila, Di Cavalcanti, Cuignard, Cícero Dias e Portinari, com a arte cubista e o pensamento em torno da arte moderna europeia.

A exiguidade do tempo e a impropriedade da ocasião, não permitiram um estudo mais ou menos sério que focalizasse as relações das artes plásticas, no Brasil, com as nossas tradições históricas e a nossa realidade presente; a função social da pintura entre nós (MARTINS, 1937, p. 7)

Segundo o autor, em uma palestra de 40 minutos conseguiu somente apresentar "uma síntese das atividades e dos valores da pintura moderna entre nós" (MARTINS, 1937, p. 7), tendo como objetivo final fazer uma avaliação da função da arte engajada politicamente, debate este presente no final dos anos 1930. Começa o texto fazen- do uma análise da obra da Tarsila do Amaral, de quem era companheiro na época, e dividindo a produção da pintora em três fases: o início, com uma pintura de poeta; o período parisiense; " "a descoberta do Brasil", na fase da antropofagia - interpretação da obra de Tarsila do Amaral que servirá como modelo de análises posteriores. Em seguida, Martins faz brevíssimas análises das produções de Anita Malfatti, Hugo Adami, Santa Rosa, Di Cavalcanti, Guingard, Cícero Dias, Teruz, entre outros. Por fim, fecha a conferência falando sobre Portinari, e defendendo a pintura moderna brasileira no período como fase inaugural do processo de autonomia.

Imagem 1 - Contracapa do livro "A Pintura Moderna no Brasil", de Luis Martins (1937).

LUIS MARTINS

A Pintura Moderna

no Brasil

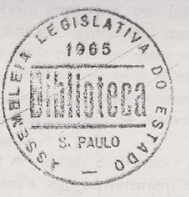

SCHMIDT editor

Fonte: Reprodução elaborada pela autora 
A conclusão final do texto é uma análise da função social da arte, na qual Martins cita dois autores que representam contextos precisamente opostos: Ceorge Plekanov, teórico marxista russo, autor de A Arte e a vida social?, de 1913 - leitura obrigatória entre os comunistas brasileiros; e Cuillaume Apollinaire, literato francês apreciadíssimo entre os modernistas brasileiros. O autor assume as palavras do poeta francês ao transcrever o seguinte texto: "Os grandes poetas e os grandes artistas têm como função social renovar sem cessar a aparência que reveste a natureza aos olhos do homem", e defende brevemente o caráter essencialmente plástico e estético das criações artísticas, sem fazer "confissões ou profissões de fé, mas como sou, por temperamento, contrário a todo 'parti-pres' e a toda atitude dogmática, acho melhor, no domínio da arte, deixar passagem aberta para todos os caminhos" (MARTINS, 1937). E termina com o seguinte texto, que nos deixa vislumbrar uma intenção de fazer-se uma historia das artes visuais focada em análises que, hoje, chamaríamos de formalistas:

7 A publicação desta obra no Brasil data de 1969, mas a obra já éra conhecida antes de sua tradução.
Afirmo somente minha crença da Arte. A lição definitiva dos sécul'os é que, por cima das contingências passageiras dos homens, ela permanece, tendo a sua beleza e seu grande sentido humano dentro dela própria. Os homens que hoje se comovem diante de uma parede de Fra Angelico ou da Gioconda de Leonardo, não procuraram saber o sentido inspirador dessas maravilhosas criações, mas admiram simplesmente a obra de arte, á realização artística (MARTINS, 1937, p. 56).

Esta crítica ligeira, no formato de uma conferência publicada em livró (Imagem 1), desempenha o papel de iniciar publicações mais sistemáticas sobre o amplo debate que vinha ocorrendo nos jornais, revistas e catálogos de exposição, e concretiza o anseio de se sistematizar a história do recentíssimo modernismo no Brasil.

\section{0 anos da Semana de Arte Moderna: a conferência de Mario de Andrade em 1942}

Em 1942, por ocasião dos 20 anos da Semana de Arte Moderna, Mario de Andrade faz uma conferência no Ministério das Relações Exteriores, no Rio de Janeiro, que posteriormente foi 
publicada com o título de O movimento modernista, sendo que esta publicação constituirá momento de importante inflexão crítica que o poeta fez em seu autoexílio no Rio de Janeiro. Andrade (1967 [1942], p. 265) inicia o texto com a seguinte advertência: "Não cabe neste discurso de caráter polêmico, o processo analítico do movimento modernista.

Mario de Andrade coloca, logo no início do texto, que o evento foi eleito como o principal marco "preparador e por muitas vezes, criador de um estado de espírito nacional", mas ao mesmo tempo faz uma observação irônica ao afirmar "que tudo quanto fez o movimento modernista, far-se-ia da mesma forma sem o movimento", sentenciando que "A Semana é uma data, isso é inegável", mas que existiria uma pré-consciência. E parte importante desta consciência devia-se ao fato de que, no momento da exposição de Anita Malfatti de 1917,"ignorando Cezanne", um "grupinho de intelectuais paulistas" aderiu incondicionalmente à arte cubista e expressionista de pintora recém-chegada de seu período de formação no atelier de Homer Boss, em Nova York. Fato que, somado à necessidade da renovação do meio e à empolgação do "mestre" Graça Aranha, juntamente com o patrocínio de Paulo
Prado, na visão de Mario de Andrade teria resultado na organização deste festival de arte moderna.

Interessante observarque, neste mesmo relato, ao lado da importância destacada para a obra de Victor Brecheret (que teria sido "descoberto" pelos modernistas em seu ateliê no Palácio das Indústrias), Andrade faz uma análise positiva do papel de Monteiro Lobato como editor de vanguarda. Sua interpretação dos fatos que antecederam a Semana é cheia de ambiguidades, porém procura matizar o quadro dos acontecimentos e das referências, servindo de inegável fonte neste momento de reavaliação do movimento por um dos seus mais importantes integrantes.

E, por fim, Andrade faz referência a Sergio Milliet e sua "serenidade equilibrada", destacando a importância dos Salões dos'anos 1930 como fator difusor de um "espírito destruidor do movimento modernista", e criticando o caráter não sério do movimento, que foi acolhido por uma aristocracia rural e tradicional e não pela nova aristocracia urbana: "Nenhum salão de ricaço tivemos, nenhum milionário estrangeiro nos acoIheu. Os italianos, alemães, os israelitas 
se faziam de mais guardadores do bom-senso nacional que Prados e Penteados e Amarais" (ANDRADE, 1967 [1942], p. 264).

\section{A Arte Moderna instituída: Sergio Milliet, Lourival Gomes Machado e Mario Pedrosa}

Sergio Milliet foi um dos mais importantes intelectuais no Brasil nestes anos de 1940. Poeta e sociólogo, atuou intensamente no campo da crítica de arte, tendo participado continuamente dos debates nos jornais, e como dirigente de importantes instituições, como o Museu de Arte Moderna e a Biblioteca Municipal de São Paulo. Nestes anos, publica seus ensaios sobre arte em Pintores e Pintura (1940), O Sal da Heresia (1941), Fora de Forma (1942a), e A Marginalidade da Pintura Moderna (1942b - Imagem 2). Este último texto foi reeditado em Pintura quase sempre (1944) e apresenta uma análise sociológica sobre as condições de criação da arte de ruptura, do período pré-renascentista ao surrealismo. Neste texto audacioso, a pretensão de Milliet foi fazer uma história universal da for- ma, a partir de uma sensibilidade modernista, que no Brasil constituía uma novidade em oposição ao ensino tradicional da história da arte. Essencialmente um livro de divulgação, a publicação expressa a vontade de se formar uma bibliografia sobre a história da arte moderna, valendo-se da sociologia, da antropologia e da etnografia, tendo como base conceitual os trabalhos The marginal Man, de Everett Stonequist (1937), e As Origens da Arte, de Ernst Crosse, este editado no Brasil em 19438. Segundo Conçalves (1992, p. 120), "para didátizar a compreensão do que é a arte moderna, Sergio Milliet constrói um modelo explicativo, baseando-se na questão do divórcio arte/público".

Pensando no contexto nacional, e especialmente no paulista, Milliet polemiza com uma concepção, então vigente na crítica de arte, que defendia a relação necessária entre a arte e os processos econômicos, em especial a partir do trabalho de Luis Martins, que tinha acabado de apresentar uma análise da pintura paulista, em que relacionava o rebaixamento da paleta com a crise econômica da cafeicultura paulista?.

8 Cf. Gonçalves (1992).

9 Idem. 
Cinco anos depois, ocorre o lançamento do livro Retrato da Arte Moderna do Brasil (Imagem 3), ensaio publicado pelo então jovem crítico Lourival Comes Machado (1947). Proveniente dos quadros da USP e já atuante na Revista Clima (PONTES, 1998), o autor faz uma primeira elaboração sobre os caminhos possíveis para a análise sociológica da história da arte no Brasil, o que está indicado no subtítulo "análise históricosociológica".

Neste ensaio, a arte moderna é caracterizada pela "superação da fidelidade fotográfica pelos intuitos mais artísticos". O texto é emblemático da situação que se encontrava a bibliografia sobre arte moderna brasileira neste final dos anos de 1940 , e anuncia que ainda não se tinha escrito a historia da arte do Brasil, apontada como necessária.

Dividido em três capítulos - a saber: A Paisagem ao fundo; Esboço de uma Figura, da Fonte a ao Peito; e Desenvolvimento da Composição: Linhas de força e equilíbrio de volumes - Machado utiliza a metáfora das técnicas de composição na pintura para expor sua metodologia. O autor define como seú principal objetivo "escancarar uma porta por onde possam passa'r aqueles que creem na história como luta humana e nas nacionalidades como construção sofrida e conquistada" (MACHADO, 1947), o que podemos traduzir como a necessidade de se estabelecer bases metodológicas para a escritura de uma história da arte no Brasil. Muitas das ideias esboçadas no primeiro capítulo, que trata do período colonial ao final do século XIX, serão posteriormente desenvolvidas em seus estudos sobre a arte barroca.

\section{Imagem 2 - Capa do livro "Marginalidade da Pintura Moderna", de Sérgio Milliet (1942).}
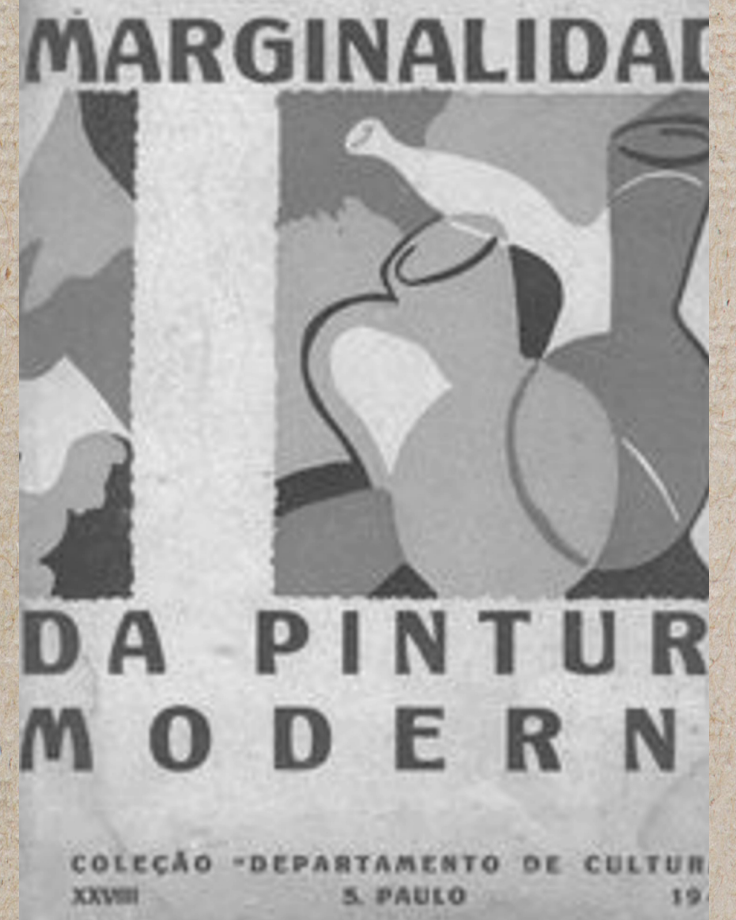

Fonte: Reprodução elaborada pela autora.

Nas palavras de Ana Cândida Avelar (2010, p. 1713),

Nele, o autor cria um lastro, baseado no barroco mineiro e em particular no Alei- 
jadinho, para os modernistas: tanto para os que provêm da Semana de 1922, como Anita, Di Cavalcanti, Brecheret, como para Tarsila e Segall. Indica ainda a continuidade desse primeiro modernismo numa segunda fase representada, para ele, por Portinari e Guignard.

Estes dois últimos capítulos irão, respectivamente, tematizar a arte do início do século XX em duas fases, permitindo ao autor fazer sua avaliação do cenário da pintura moderna no Brasil, em que elenca um panteon de artistas que formariam o "retrato". Em diálogo claro com a conferência de Mario de Andrade, citada no início do capítulo 3, o autor faz uma descrição dos fenômenos geográficos e socioeconômicos, para alinhar os artistas de maior destaque no cenário do modernismo.

Imagem 3 - Contracapa do livro "Retrato da Arte Moderna no Brasil", de Lourival Comes Machado (1948).

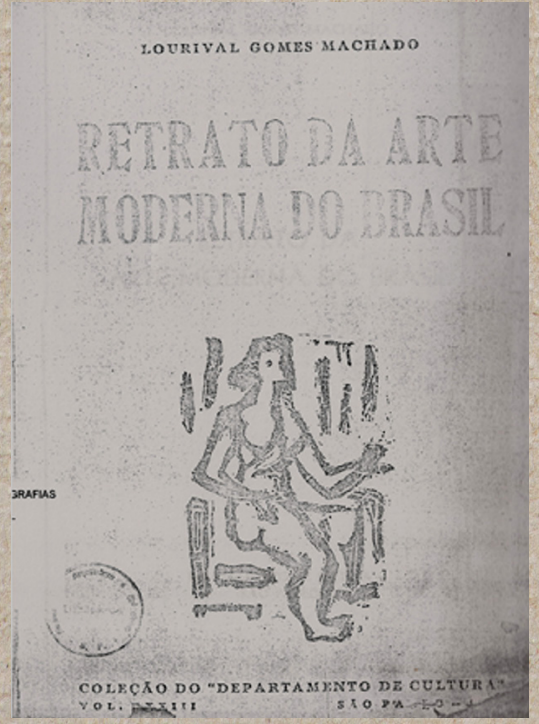

Fonte: R'eprodução elaborada pela autora.
Por fim, gostaria de citar brevemente o livro Panorama da pintura moderna (Imagem 4), de Mario Pedrosa (1952), pelo, seu caráter igualmente didático sobre a história-da arte moderna e suas conexões como desenvolvimento do modernismo no Brasil, ao qual o autor dedica poucas páginas. Chamo atenção para o manifesto expresso no único nome brasileiro: Abraam Palatinik, citado em nota como precursor da arte cinética no Brasil.

Para concluir, podemos dizer que a "chegada da arte moderna no Brasil"10 foi um processo gradativo, que contou

Imagem 4-Capa do livro "Panorama da Pintura Moderna", de Mário Pedrosa (7952).

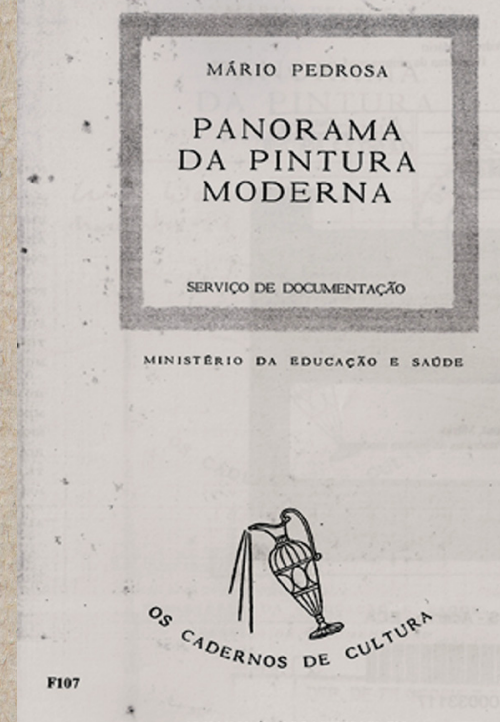

Fonte: Reprodução elaborada pela autora.

10 Tomo emprestado o título da palestra proferida por Tarsila do Amaral na Pinacoteca do Estado de São Paulo, em 1951, publicada em Milliet (2005). 
com a organização de mostras de artistas brasileiros chegados de sua formação no exterior, de estrangeiros imigrados e de mostras coletivas, como a Semana de Arte Moderna, assim como a reformulação das mostras tradicionais, como o Salão de Belas Artes e o Salão Paulista. Estes eventos foram mote de extensas polêmicas e reavaliações durante toda a primeira metade do século $X X$, e em especial nas décadas de 1940 e 1950, possibilitando algumas iniciativas de formulações da história da arte moderna no Brasil, assim como da história da arte moderna universal e suas relações possíveis com o então acanhado ambiente artístiço brasileiro.

Muitas destas iniciativas foram objeto de publicações, o que demostra o interesse público pela institucionalização do debate, paralelamente à organização de mostras coletivas e individuais, que culminaram na criação dos museus de arte moderna, na re-, formulação das mostras competitivas e na criação da Bienal do Museu de Arte Moderna de São Paulo, que teve papel importante na promoção do debate sobre o modernismo e a confrontação com a arte contemporânea. Todos esses processos ganham monta se observarmos um dos assuntos que regem as reflexões: a identidade e o lugar da produção brasileira e suas possíveis relações com a arte mundial. Ressalto que essas relações são estabelecidas nas qualidades intrínsecas às obras e aos textos críticos e teóricos. Acompanhar esses processos de criação do discurso equivale a torná-los históricos e agregar a eles importância como fonte primária, que muitas vezes tem uma função documental, mas pode ter outra, igualmente potente: a pedagógica. 


\section{Referências}

AMARAL, Aracy. Artes Plásticas na Semana de 22: subsídios para uma história da renovação das artes no Brasil. São Paulo: Perspectiva, 1970.

ANDRADE, Mario de. (1942). O movimentó modernista. Rio de Janeiro: Casa do Estudante do Brasil, 1963.

(1922). Prefácio interessantíssimo. In: Paulicéia Desvairada. São Paulo: Casa Mayença, 1922.

(1925). A escrava que não élsaura: discurso sobre algumas tendências da poesia modernista. São Paulo: SCP, 1925.

ARANHA, Craça. Espírito moderno. São Paulo: Monteiro Lobato, 1925.

Futurismo manifestos de Marinetti e seus companheiros (Prefácio). In: MARINETTI, Filippo Tommaso. Futurismo. Rio de Janeiro: Pimenta de Mello, 1926.

BATISTA, Marta Rosseti. Mário de Andrade - cartas a Anita Malfatti. Rio de Janeiro: Forense Universitária, 1989.

GONÇALVES, Lisbeth Rebollo. Sérgio Milliet, crítico de arte. São Paulo: Edusp; Perspectiva, 1992.

GROSSE, Ernst. Origens da arte. São Paulo: Cultura, 1943.

FABRIS, Annateresa. Futurismo paulista: hipóteses para o estudo da chegada da vanguarda ao Brasil. São Paulo: Edusp; Perspectiva, 1990.

Annateresa (Org.). Modernidade e modernismo no Brasil. 2. ed. rev. Porto Alegre: Zouk, 2010.

KANTOR, Sybil Cordon. Alfred H. Barr]r. and the intellectual origins of the museum of modern art. Cambridge: MIT, 2002.

KLAXON [Revista mensal de arte moderna]. São Paulo, [s.n.], 1922-1923.

LOURENÇO, Maria Cecilia Franca. Museus acolhem o moderno. São Paulo: Edusp, 1999.

MARTINS, Luis. A pintura moderna no Brasil. Rio de Janeiro: Schmidt, 1937.

MILLIET, Sergio. Pintores e pinturas. São Paulo: Martins, 1940.

O sal da heresia. São Paulo: Departamento de Cultura, 1941. 
Fora de forma. São Paulo: Anchieta, 1942a.

Marginalidade da Pintura Moderna. São Paulo: Departamento de Cultura, 1942b. (Coleção Departamento de Cultura).

Pintura quase sempre. Porto Alegre: Globo, 1944.

MILLIET, Maria Alice (Coord.). Mestres do Modernismo. São Paulo: Imprensa Oficial, 2005.

MACHADO, Lourival Comes. Retrato da Arte Moderna no Brasil. São Paulo: Departamento de Cultura, 1947.

STONEQUIST, Everett $V$. The marginal man: a study in personality and culture conflict. New York: Scribner; Simon \& Schuster, 1937.

PEDROSA, Mario. Panorama da pintura moderna. Rio de Janeiro: Ministério da Educação e Saúde, Serviço de Documentação, 1952.

PONTES, Heloisa Andrade. Destinos mistos os críticos do grupo clima em São Paulo (1940-68). São Paulo: Companhia dás Letras, 1998.

PLEKHANOV, Georgii Valentinovich. (1913): A arte e a vida social. 2. ed. Trad. Eduardo Sucupira Filho. São Paulo: Brasiliense, 1969.

RASM - Revista Anual do Salão de Maio. São Paulo, [s.n.], 1938. 
